Billimoria, J. D., Curtis, R. G. \& Maclagan, N. F. (1960). Biochem. J. 78, 185.

Curragh, E. F. \& Elmore, D. T. (1962). J. chem. Soc. p. 2948.

Curragh, E. F. \& Elmore, D. T. (1963). Biochem. J. 86, 9 P.

Ebata, M. (1961). J. Biochem., Tokyo, 49, 110.

Ehrenpreis, S. \& Scheraga, H. A. (1957). J. biol. Chem. 227, 1043.

Elmore, D. T., Kingston, A. E. \& Shields, D. B. (1963). J. chem. Soc. p. 2070.

Elmore, D. T., Ogle, J. R. \& Toseland, P. A. (1956). J. chem. Soc. p. 192.

Foster, R. J. (1961). J. biol. Chem. 236, 2461.

Garagnani, A. \& Facchini, G. (1956). Arch. Pat. Clin. med. 33, 203.

Gutfreund, H. \& Sturtevant, J. M. (1956a). Proc. nat. Acad. Sci., Wash., 42, 719.

Gutfreund, H. \& Sturtevant, J. M. (1956b). Biochem. J. 63, 656.

Jirgensons, B. (1961). Arch. Biochem. Biophys. 94, 59.
Jirgensons, B. (1962a). Arch. Biochem. Biophys. 96, 321.

Jirgensons, B. (1962b). Makromol. Chem. 56, 138.

Johnson, J. F. \& Seegers, W. H. (1955). In The Coagulation of Blood, p. 121. Ed. by L. M. Tocantins. New York: Grune and Stratton Inc.

Koshland, D. E. (1958). Proc. nat. Acad. Sci., Wash., 44, 78.

Marciniak, E. \& Seegers, W. H. (1962). Canad. J. Biochem. Physiol. 40, 597.

Mustard, J. F., Medway, W., Downie, H. G. \& Rowsell, H. C. (1962). Nature, Lond., 196, 1063.

Ronwin, E. (1959). Biochim. biophys. Acta, 33, 326.

Scheraga, H. A. \& Ehrenpreis, S. (1958). Symp. 4 th int. Congr. Biochem., Vienna, vol. 10, p. 212.

Schwert, G. W. \& Eisenberg, M. A. (1949). J. biol. Chem. $179,665$.

Sherry, S. \& Troll, W. (1954). J. biol. Chem. 208, 95.

Trowbridge, C. G., Krehbiel, A. \& Laskowski, M. (1963). Biochemistry, 2, 843.

Wenzel, D. G. \& Singh, J. (1962). J. pharm. Sci. 51, 875.

Biochem. J. (1964), 93, 171

\title{
The Purification and Properties of Human Plasminogen
}

\author{
By NORMA ALKJAERSIG \\ Department of Medicine, Washington University School of Medicine, St Louis, Mo., U.S.A.
}

(Received 23 December 1963)

The purification of plasminogen has presented problems of special difficulty. Earlier procedures (Milstone, 1941 ; Remmert \& Cohen, 1949; Fletcher, 1954) yielded material that was relatively stable and soluble at neutral $\mathrm{pH}$, but of low specific activity. On the other hand, the acid-extraction method of Christensen \& Smith (1950), which has also been used in the work of Kline (1953), Sgouris, Inman, McCall, Hyndman \& Anderson (1960), Shulman (1961) and Kline \& Fishman (1961), yields material of greater specific activity, but of very limited stability and solubility at neutral $\mathrm{pH}$. These properties of the purified protein are unexpected, since plasminogen occurs in plasma in a form that is both stable and soluble at neutral $\mathrm{pH}$. Consequently it would seem that the acid extraction of Cohn fraction III, which is the first step in the Christensen \& Smith (1950) procedure, causes some alteration in the plasminogen molecule, which is reflected in a change of physical but probably not of biochemical properties.

Alkjaersig (1960) presented preliminary results on the purification of plasminogen by DEAEcellulose chromatography without extreme, especially acid, $\mathrm{pH}$ changes. The product possessed approximately equivalent specific activity to that prepared by acid-extraction procedures, was highly soluble in neutral $\mathrm{pH}$ buffers and was relatively stable under these conditions. Wallen \& Bergström $(1959,1960)$ independently reported preliminary findings on a DEAE-cellulose-chromatographic method for plasminogen purification utilizing the solvent effects of lysine for plasminogen elution; several similar reports (Hagan, Ablondi \& De Renzo, 1960; Davies \& Englert, 1960; Wallen, 1962 $a, b$; Derechin, 1962; Derechin, Johnson \& Szuchet, 1962; Robbins \& Summaria, 1963; Hink \& McDonald, 1962) have recently appeared, but, though the preparations have been reported to be of comparable specific activity, only sparse and somewhat discrepant information has been made available on protein properties.

Since preliminary results suggested that proteinsedimentation parameters might be influenced by treatment with $\epsilon$-aminohexanoic acid, two alternative purification procedures have been developed, one of which utilizes the selective solvation properties of $\epsilon$-aminohexanoic acid and the other does not. The results obtained with these new preparations have confirmed earlier activation (Alkjaersig, Fletcher \& Sherry, 1958a, b) and biophysical (Shulman, Alkjaersig \& Sherry, 1958) studies with 
plasminogen prepared by acid-extraction procedures. Moreover, the present results suggest that the plasminogen molecule possesses unusual structural plasticity and may, under defined conditions, exist in one of three structural configurations. Biophysical parameters for these structural configurations are characteristic and interconversion, without denaturation, of one form into another has been demonstrated. For descriptive convenience, plasminogen prepared by acid-extraction procedures is termed plasminogen $A$ and plasminogen purified by DEAE-cellulose column chromato. graphy and at no time exposed to acid conditions is designated plasminogen $B$.

\section{MATERIALS AND METHODS}

Determination of protein. Total protein, as tyrosine colour equivalents, was assayed by using the Folin-Ciocalteu reagent (Heidelberger \& MacPherson, 1943).

Determination of plasminogen and plasmin. Plasminogen was determined in plasma and serum after destruction of inhibitors (Alkjaersig, Fletcher \& Sherry, 1959a). Plasminogen and plasmin in purified fractions were determined by methods described by Alkjaersig, Fletcher \& Sherry (1959b), the results being expressed as casein units. Comparison of this casein unit with that of a proposed standard plasmin, kindly supplied by Dr Alan Johnson, indicated that the proposed standard casein unit is equivalent to 1.5 of the present units.

The plasminogen content of polyacrylamide-gel slices was assayed, after electrophoresis in this medium, by freezing (in acetone-solid $\mathrm{CO}_{2}$ mixture) $0.5 \mathrm{~cm}$. gel slices in individual tubes containing $1 \mathrm{ml}$. of phosphate buffer $\left(0 \cdot 1 \mathrm{M}-\mathrm{NaH}_{2} \mathrm{PO}_{4}\right.$ adjusted to $\mathrm{pH} 7 \cdot 6$ with $\mathrm{N}-\mathrm{NaOH}$ ) where plasminogen $B$ was being examined and $1 \mathrm{ml}$. of $0.01 \mathrm{~N}-\mathrm{HCl}$ where plasminogen $A$ was used. On being thawed, the gel residue was separated by mechanical compression and the supernatant assayed by a micro modification of the casein method with streptokinase (Varidase, generously supplied by Lederle Laboratories, Pearl River, N.Y., U.S.A.) or urokinase (kindly supplied by Abbott Laboratories, North Chicago, Ill., U.S.A., and Sterling-Winthrop Laboratories, Rensselaer, N.Y., U.S.A.) used as activators.

Kinetic studies. Activation kinetics were determined after halting the reaction with $\epsilon$-aminohexanoic acid. Portions ( $4 \mathrm{ml}$ ) of plasminogen (5 casein units $/ \mathrm{ml}$.) were udded to $0.4 \mathrm{ml}$. portions of streptokinase of various concentrations. The tubes were incubated at $30^{\circ}$; at intervals $0.5 \mathrm{ml}$. portions were added to $0.5 \mathrm{ml}$. portions of $\epsilon$-aminohexanoic acid $(26 \mathrm{mg} . / \mathrm{ml}$.). Plasmin and remaining plasminogen were determined by the casein assay, the final concentration of $\epsilon$-aminohexanoic acid in the assay tube being $0.02 \mathrm{M}$; at this concentration activation was effectively inhibited, and plasmin activity was enhanced by about $10 \%$ (Alkjaersig et al. 1959 b).

Fibrin-plate assay. Plasmin and plasminogen were assayed by the fibrin-plate method, by a modification (Alkjaersig et al. 1959 b) of Astrup's technique.

Ultracentrifugation. A Spinco (Beckman-Spinco, Palo Alto, Calif., U.S.A.) model $\mathbf{E}$ analytical ultracentrifuge, calibrated by means of a standard Spinco calibration cell, was used for ultracentrifugal studies. The plate patterns were projected at $10 \times$ magnification with a Nikon Shadowgraph (Nippon Kogaku, Tokyo, Japan) and pattern measurements made by stage micrometers. Pattern area measurements were made, after double-sector-cell runs, by tracing the enlarged image and the use of a planimeter. Sedimentation-velocity calculations were made with the usual corrections (Schachman, 1959).

The apparent diffusion coefficients were calculated from the equation:

$$
D_{\text {app. }}=\frac{A^{2}}{H^{2}} \times \frac{1}{t} \times \frac{1}{4 \pi} \times \omega^{2}
$$

in which $A$ is the area under the peak, $H$ is the maximum height, $t$ is time in seconds, with allowance made for the time of rotor acceleration, and $\omega$ is the enlargement factor converting measurement of the tracing to centimetres in the

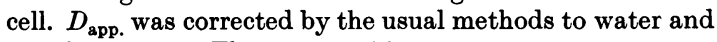
$20^{\circ}$ (Svensson \& Thompson, 1961).

Electrophoresis. Boundary electrophoresis (Tiselius) was performed in a Perkin-Elmer model $38 \mathrm{~A}$ apparatus (Perkin-Elmer Corp., Norwalk, Conn., U.S.A.), the $2 \mathrm{ml}$. cell being employed. Runs were made with $0 \cdot 1$ ionic strength glycine, acetate, phosphate and barbital buffers. The adequacy of dialysis was checked by conductivity measurements. Zone electrophoresis (model 12 a apparatus; Canal Industrial Corp., Bethesda, Md., U.S.A.) was performed with polyacrylamide gels of $\mathbf{7 . 5}$ and $15 \%(w / v)$ concentrations, the gels having a diameter of $8 \mathrm{~mm}$. Immunoelectrophoresis was performed by incorporating the polyacrylamide gels in agar and performing diffusion in this medium. The antiserum (Mann Laboratories, New York, N.Y., U.S.A.) was of rabbit origin prepared against human-plasma fraction III.

Preparation of euglobulin fraction. Time-expired human blood-bank plasma ( $800 \mathrm{ml}$.) was defibrinated by the addition of calcium chloride to a concentration of $25 \mathrm{~mm}$ and then three $1 \mathrm{ml}$. portions of thrombin (100 units $/ \mathrm{ml}$.) under constant stirring with applicator sticks. The defibrinated plasma was diluted to $16 \mathrm{l}$. with distilled water and adjusted to $\mathrm{pH} 5 \cdot 3$ with $10 \%(\mathrm{v} / \mathrm{v})$ acetic acid; after settling overnight at $2^{\circ}$, the supernatant was siphoned off and the precipitate collected by centrifugation. The precipitate was dissolved in $200 \mathrm{ml}$. of $0.01 \mathrm{M}-\mathrm{Na}_{2} \mathrm{HPO}_{4}$ adjusted to $\mathrm{pH} 8.5$ with $\mathrm{N}-\mathrm{HCl}$, dialysed against $5 \mathrm{l}$. of the same buffer, centrifuged at $16000 \mathrm{rev} . / \mathrm{min}$. $(33000 \mathrm{~g})$ and filtered through Whatman no. 2 paper; the resulting somewhat turbid solution was used for chromatography. Table 1 gives representative findings with one of these preparations. The specific activity of plasminogen in the euglobulin fraction ranged from 9 to 18 casein units $/ \mathrm{mg}$. of tyrosine equiv.

Pretreatment of fraction III. A sample (40 g.) of Cohn fraction III (obtained through the courtesy of the American Red Cross from E. R. Squibb and Sons) was suspended in $800 \mathrm{ml}$. of $5 \mathrm{~mm}-\mathrm{NaH}_{2} \mathrm{PO}_{4}-0.04 \mathrm{M}$-tris buffer, $\mathrm{pH} 8.9$, containing $1 \mathrm{~g}$. of $\epsilon$-aminohexanoic acid; a Waring Blendor was used to make a smooth suspension. The suspension was centrifuged and the precipitate re-extracted as described above. The combined extracts were adjusted to $\mathrm{pH} 5 \cdot 3$ and the precipitate was discarded. With most, but not all, batches of fraction III, a gelatinous precipitate was formed on adjustment of the relatively clear supernatant to $\mathrm{pH} 6 \cdot 0$ 6.5 with $\mathrm{N}-\mathrm{NaOH}$. After centrifugation, the clear supernatant was adjusted to $\mathrm{pH} 7 \cdot 0$ and taken to $40 \%$ satura- 
tion with ammonium sulphate. The precipitate was dissolved in $100 \mathrm{ml}$. of $5 \mathrm{~mm}-\mathrm{NaH}_{2} \mathrm{PO}_{4}-0.04 \mathrm{M}$-tris buffer, $\mathrm{pH} 8.9$, and dialysed against $5 \mathrm{l}$. of the same buffer overnight. The supernatant was diluted tenfold with distilled water and adjusted to $\mathrm{pH} \mathrm{5 \cdot 3}$. The precipitate was dissolved in $50 \mathrm{ml}$. of the starting buffer and dialysed against the same buffer before application to the column.

Table 1 shows the recovery and degree of purification of one of these preparations. The specific activity of plasminogen in the final precipitate has ranged from 36 to 70 casein units/mg. of tyrosine equiv.

Chromatography on diethylaminoethylcellulose. A $2.5 \mathrm{~cm}$. $\times 40 \mathrm{~cm}$. column was packed with approximately $16 \mathrm{~g}$. of DEAE-cellulose (Brown and Co., Berlin, N.H., U.S.A.) equilibrated with the starting buffer, $0.01 \mathrm{M}$-phosphate, $\mathrm{pH}$ 8.5. The euglobulin fraction from human plasma was applied to the column and washed with $200 \mathrm{ml}$. of starting buffer. Buffer gradients were produced by the method of Fahey, McCoy \& Goulian (1958) with a 1 l. round-bottomed flask containing starting buffer (0.01 m-phosphate, $\mathrm{pH} \mathrm{8.5)}$ serving as a mixing chamber and connected with a $500 \mathrm{ml}$. Erlenmeyer flask containing limit buffer $\left(0 \cdot 3 \mathrm{M}-\mathrm{NaH}_{2} \mathrm{PO}_{4}\right.$ buffer adjusted to $\mathrm{pH} 6.5$ with $2 \mathrm{~N}-\mathrm{NaOH})$. Individual effluent volumes were $10-20 \mathrm{ml}$. and flow rates were 40 $60 \mathrm{ml} . / \mathrm{hr}$.

Chromatography on diethylaminoethyl-Sephadex. A slurry of 20-25 g. of DEAE-Sephadex G-50 (fine grade) (Pharmacia, Uppsala, Sweden) equilibrated with starting buffer, $5 \mathrm{~mm}-\mathrm{NaH}_{2} \mathrm{PO}_{4}-0.04 \mathrm{M}$-tris buffer, $\mathrm{pH} \mathrm{8.9}$, was added to a $4 \mathrm{~cm} . \times 40 \mathrm{~cm}$. column. An extract of Cohn fraction III (see above) was applied to the packed column, and the column was washed with starting buffer. A defined elution gradient was obtained by the use of a Varigrad device with nine chambers (Peterson \& Sober, 1961). The limit buffer was $0.2 \mathrm{M}-\mathrm{NaH}_{2} \mathrm{PO}_{4}-0 \cdot 2 \mathrm{M}$-tris buffer, $\mathrm{pH} 7 \cdot 5$, which served as stock solution for the buffers in the other Varigrad chambers. The buffer distribution for the most often used gradient was as follows (200 ml. in each chamber): 1 , starting buffer; 2 and 3, 0.05 M-phosphate-0.05 M-tris buffer; 4 and 7, 0.1 M-phosphate-0.1 M-tris buffer; 5 and 9, limit buffer; 6, distilled water or in a few experiments 0.04 M-є-aminohexanoic acid; 8, 0.16 M-phosphate-0.16 Mtris buffer.

Columns of fine-grade DEAE-Sephadex frequently flow too slowly; adequate flow rates $(60-100 \mathrm{ml} . / \mathrm{hr}$.) were obtained by careful removal of fines, and running the columns under 5-7 lb./in. ${ }^{2}$ air pressure by using a capacitance-measurement relay connected to a pump feed to control column hydrostatic level. Individual effluent volumes varied from 15 to $24 \mathrm{ml}$. in different experiments.

\section{RESULTS}

Method 1: diethylaminoethylcellulose chromatography. Fig. 1 demonstrates the elution diagram for a DEAE-cellulose column. Fig. $1(b)$ shows serial conductivity and $\mathrm{pH}$ measurements and Fig. 1 $(a)$ tyrosine and plasminogen assays in pooled specimens from five $20 \mathrm{ml}$. fractions; individual tube assays were performed in the fractions containing the plasminogen peak. The initial effluent fractions contained large quantities of tyrosine-reacting material but virtually no plasminogen.
The plasminogen content and specific activity (expressed as casein units/mg. of tyrosine equiv.) of the original plasma, of the euglobulin fraction used for chromatography and of the effluent fractions are shown in Table 1. Preparation of the euglobulin fraction from plasma was accomplished with little loss, but the specific activity of the product was low ( $12 \cdot 2$ casein units/mg. of tyrosine equiv.). A tenfold further purification in an overall yield of $60 \%$ resulted from chromatography on DEAE-cellulose (Fig. 1). The specific activity of the material in effluent fractions 35-50 was about 125 casein units/ mg. of tyrosine equiv., whereas that in fractions 4048 was 160 casein units/mg. of tyrosine equiv. and represented a recovery of $40 \%$ of the material applied to the column. The highest specific activity found by this method of purification has been 190 casein units/mg. of tyrosine equiv.

Method 2: use of Cohn plasma fraction III and diethylaminoethyl-Sephadex chromatography. Cohn plasma fraction III represents a convenient starting material for large-scale preparative plasminogen purification, and treatment of this fraction by the method described above gave clear concentrated plasminogen solutions well suited to chromatographic purposes. This purification procedure was highly reproducible with all lots of fraction III in our possession; the yields and specific activities at various stages are shown in Table 1.

Reproducible elution patterns were obtained after column chromatography of this preparation on DEAE-Sephadex ; representative findings, from a single run, are displayed in Fig. 2. Conductivity and $\mathrm{pH}$ determinations are shown in Fig. 2(b), and plasminogen and tyrosine assays in Fig. 2(a). Tubes 20-30 contained the main plasminogen peak,

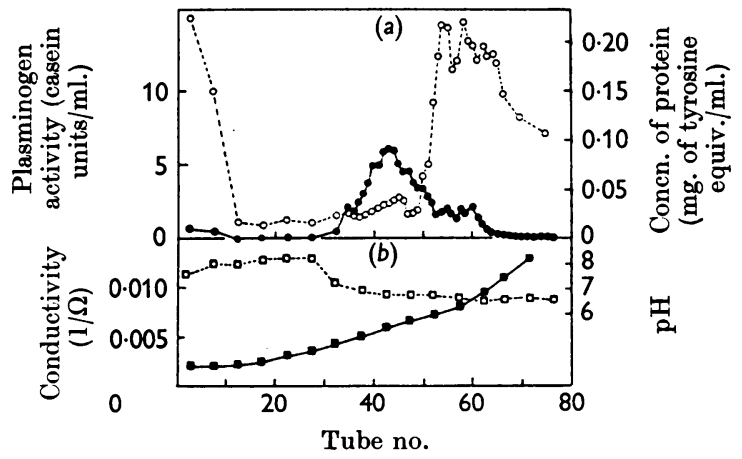

Fig. 1. Elution diagram of DEAE-cellulose column (method 1). (a) Plasminogen ( $($ ) and protein (tyrosine equiv.) (O) determinations; $(b)$ conductivity $(\square)$ and $\mathrm{pH}$ ( $\square$ ) measurements. The column size was $2 \cdot 5 \mathrm{~cm} . \times 40 \mathrm{~cm}$. The volume of each fraction was $20 \mathrm{ml}$. The starting buffer was $0.01 \mathrm{M}$-phosphate buffer, $\mathrm{pH} 8.5$, and the limit buffer $0 \cdot 3 \mathrm{~m}$-phosphate buffer, $\mathrm{pH} 6.5$. 
with tubes 24-27 having the highest specific activity. Of the material applied to the column $46 \%$ was recovered in the peak fraction with a mean specific activity of 189 casein units/mg. of tyrosine equiv. Table 1 demonstrates a $2 \cdot 6$-fold purification over the partially purified starting material for the major portion of the elution peak. In other runs the specific activity of the best plasminogen fractions ranged from 180 to 230 casein units/mg. of tyrosine equiv.

Rechromatography of a peak fraction ( 180 casein units/mg. of tyrosine equiv.) under similar conditions to those described above gave a single sharp elution peak at identical buffer $\mathrm{pH}$ and conductivity values to those previously observed (yield $80 \%$ of the applied plasminogen) but of unchanged specific activity.

Properties. Plasminogen $A$ is so sparingly soluble in conventional buffers at neutral $\mathrm{pH}$ that its presence is only barely detectable by the casein assay, i.e. the solubility is less than $0.05 \mathrm{mg} . / \mathrm{ml}$. However, plasminogen $A$ preparations are extremely soluble (solubility exceeding $10 \mathrm{mg} . / \mathrm{ml}$.) in neutral buffers containing $\epsilon$-aminohexanoic acid $(0.01 \mathrm{M})$, a solubilizing procedure that has been employed to facilitate biophysical studies at neutral $\mathrm{pH}$.

The solubility properties of plasminogen $B$ preparations never exposed to extremes of $\mathrm{pH}$ are in marked contrast; these preparations are readily soluble (solubility exceeding $25 \mathrm{mg}$. $/ \mathrm{ml}$.) in conventional buffers at neutral $\mathrm{pH}$ in the absence of $\epsilon$-aminohexanoic acid.

Stability studies. Fig. 3 contrasts the stability of a plasminogen prepared by DEAE-cellulose chromatography and a preparation made by the Kline

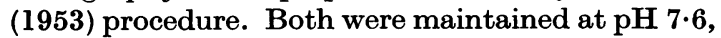
the first in solution, the latter in suspension, and kept at $4^{\circ}, 26^{\circ}$ and $37^{\circ}$. At intervals casein assays were performed with and without the addition of streptokinase. Plasminogen $B$ exhibited greater stability than plasminogen $A$, the $50 \%$ decay times being about five times as long at the various temperatures.

Plasminogen instability at neutral $\mathrm{pH}$ may result from its autocatalytic conversion into plasmin (Alkjaersig et al. 1958a), the latter enzyme being unstable. In the plasminogen $B$ series spontaneous caseinolytic activity was not detected till the fourth day and the quantities determined at this period represented $8 \%$ in the $37^{\circ}$ sample, $4 \%$ in the $26^{\circ}$ sample and $1 \%$ in the $4^{\circ}$ sample of the initial plasminogen. On the seventh day, the samples incubated at $26^{\circ}$ and $4^{\circ}$ exhibited spontaneous plasmin activity equivalent to $14 \%$ of the initial plasminogen. The identical plasminogen preparation incubated at $37^{\circ}$ in $50 \%(\mathrm{v} / \mathrm{v})$ glycerol solution (which stabilizes both plasminogen and plasmin) when assayed on the seventh day showed $15 \%$ of the original plasminogen as plasmin and no

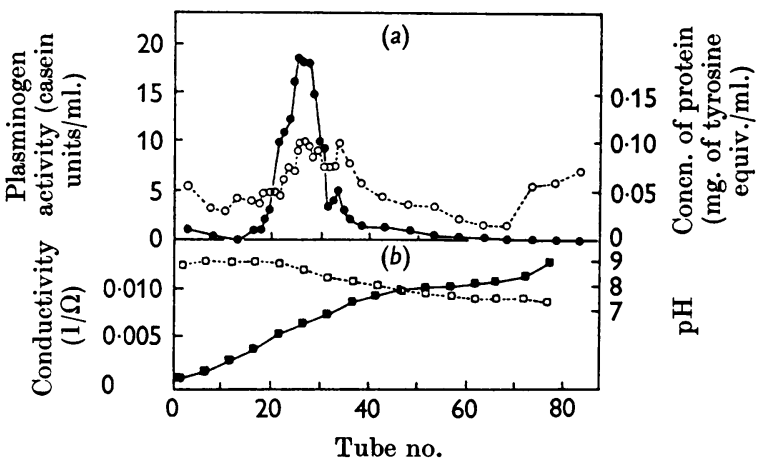

Fig. 2. Elution diagram of DEAE-Sephadex column (method 2). (a) Plasminogen (O) and protein (tyrosine equiv.) (O) determinations; (b) conductivity ( $\square$ ) and $\mathrm{pH}$ ( $\square$ ) measurements. The column size was $4 \mathrm{~cm} . \times 40 \mathrm{~cm}$. The volume of each fraction was $22 \mathrm{ml}$. The starting buffer was $5 \mathrm{~mm}-\mathrm{NaH}_{2} \mathrm{PO}_{4}-0.04 \mathrm{M}$-tris, $\mathrm{pH} 8.9$, and the limit buffer $0 \cdot 2 \mathrm{M}-\mathrm{NaH}_{2} \mathrm{PO}_{4}-0 \cdot 2 \mathrm{M}$-tris, $\mathrm{pH} 7 \cdot 5$.

Table 1. Recoveries and specific activities of plasminogen at various stages during its purification

Experimental details are given in the text.

\begin{tabular}{|c|c|c|c|c|}
\hline Fraction & $\begin{array}{l}\text { Vol. } \\
\text { (ml.) }\end{array}$ & $\begin{array}{c}\text { Activity } \\
\text { (casein units/ml.) }\end{array}$ & $\begin{array}{c}\text { Sp. activity } \\
\text { (casein units/ } \\
\text { mg. of } \\
\text { tyrosine equiv.) }\end{array}$ & $\begin{array}{l}\text { Total activity } \\
\text { (units) }\end{array}$ \\
\hline \multicolumn{5}{|l|}{ Method 1} \\
\hline Plasma & 750 & $2 \cdot 8$ & - & 2100 \\
\hline Euglobulin & 200 & $10 \cdot 1$ & $12 \cdot 2$ & 2020 \\
\hline Tubes 35-50 & 340 & $3 \cdot 5$ & 125 & 1200 \\
\hline Tubes $40-48$ & 168 & $5 \cdot 0$ & 160 & 840 \\
\hline \multicolumn{5}{|l|}{ Method 2} \\
\hline $\begin{array}{l}\text { Combined extracts of } \\
\text { Cohn fraction III }\end{array}$ & 1350 & $8 \cdot 0$ & $5 \cdot 8$ & 10830 \\
\hline$\left(\mathrm{NH}_{4}\right)_{2} \mathrm{SO}_{4} \mathrm{ppt}$ & 140 & $60 \cdot 0$ & $18 \cdot 0$ & 8400 \\
\hline pH 5.3 ppt. & 50 & $149 \cdot 0$ & $69 \cdot 0$ & 7450 \\
\hline Tubes $20-30$ & 220 & $15 \cdot 5$ & $189 \cdot 0$ & 3400 \\
\hline
\end{tabular}




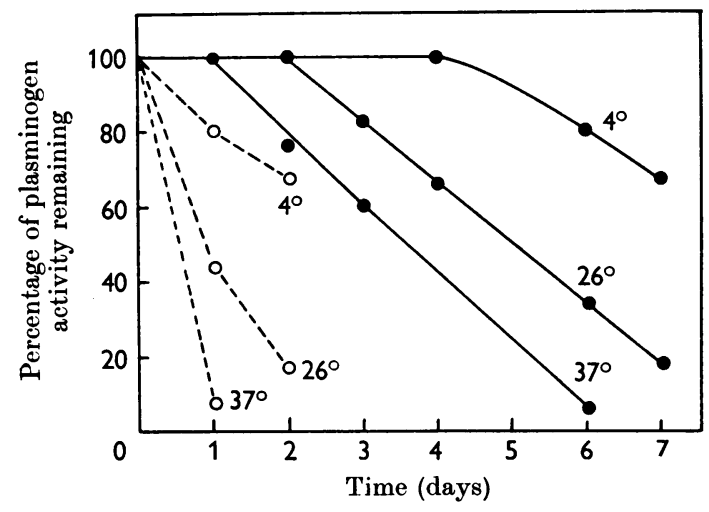

Fig. 3. Stabilities of plasminogen preparations maintained at neutral $\mathrm{pH}$ and $4^{\circ}, 26^{\circ}$ and $37^{\circ}$. O, Plasminogen $A$; plasminogen $B$.

loss when assayed by streptokinase activation. Plasminogen $A$ showed no initial spontaneous activity, but at $37^{\circ}$ a rapid increase in plasmin was seen $(12 \%$ at $1 \mathrm{hr}$.).

Proactivator content and kinetic studies. Proactivator assays were performed on plasminogen preparations $A$ and $B$; both preparations were adjusted to contain the same amount of plasminogen activity $(2.4$ casein units $/ \mathrm{ml}$.) and serial dilutions were made of each. Streptokinase (30 units/ ml.) was added to samples of each dilution, and the mixtures were applied to fibrin plates. Control sam. ples of plasmin (free of kinase and prepared by activation of plasminogen $A$ in $50 \%$ glycerol; Alkjaersig et al. 1958a) were assayed in the same manner.

Fig. 4 demonstrates that a single regression line fits the points derived from the two plasminogen preparations, suggesting that the proactivator content/plasminogen unit is the same regardless of purification procedure; the contribution by plasmin to the plate lysis is small compared with that of activator. Moreover, plasminogen $B$ samples activated with either urokinase (an activator not requiring proactivator) or streptokinase yielded identical plasmin activities.

Kinetic studies. The activation kinetics of plasminogen preparations $A$ and $B$ by streptokinase were studied under identical conditions to those previously used for the study of plasminogen $A$ activation (Alkjaersig et al. 1958b), except that with plasminogen $B$ studies the activation reaction was stopped, before assay, with $\epsilon$-aminohexanoic acid. With both types of plasminogen the initial reaction velocity was proportional to streptokinase concentration and the regression lines obtained in the two cases were indistinguishable.

Sedimentation behaviour of purified plasminogen. The sedimentation behaviour of purified plasmin- ogen is complex, is related to the method of protein purification employed and varies strikingly in different solvents and at different $\mathrm{pH}$. In this section three patterns of sedimentation behaviour are distinguished: the first that of plasminogen $B$, or plasminogen $A$ (solubilized by urea) in neutral buffers; the second that of plasminogen at $\mathrm{pH} 2 \cdot 0$; lastly, that of both plasminogens examined at neutral $\mathrm{pH}$ in the presence of $\epsilon$-aminohexanoic acid. Plasminogen $A$ was prepared by Kline \& Fishman's (1961) method.

(a) Plasminogen $B$ and plasminogen $A$ (solubilized in urea) at $\mathrm{pH} \mathbf{7 \cdot 6}$. Sedimentation data as a function of protein concentration for plasminogen $B$ run in $0 \cdot 1 \mathrm{M}$-phosphate buffer, $\mathrm{pH} \mathbf{7 \cdot 6}$, are shown in Fig. 5(a), and a representative run in Fig. 6(a). The $S_{20 \text {, w }}^{0}$ value was $4.90 \mathrm{~s}$, but the sedimentation

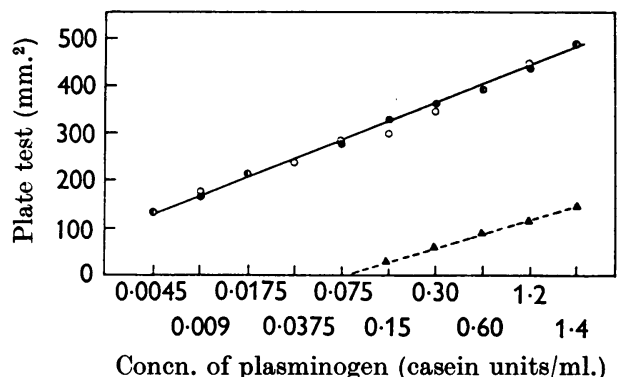

Fig. 4. Comparison of plasminogen $A(O)$ and plasminogen $B(\bigcirc)$ with regard to 'proactivator' activity. Assays were by the fibrin-plate technique. Both plasminogens, when activated with streptokinase ( $30 \mathrm{units} / \mathrm{ml}$.), gave indistinguishable lysis zones. The results were demonstrated to be largely due to proactivator content by means of the plasmin control free of kinase ( $\mathbf{\Delta})$.

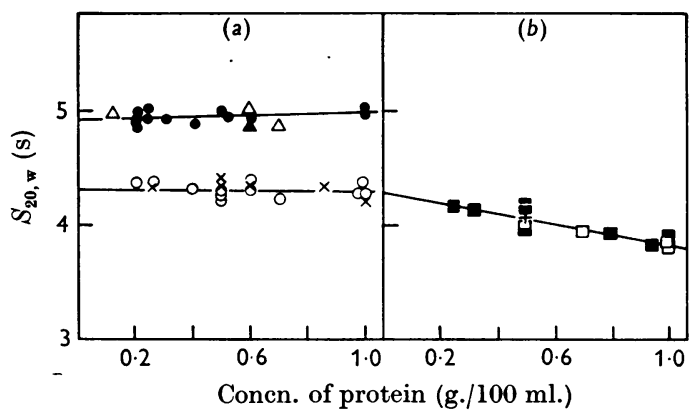

Fig. 5. $S_{\mathbf{2 0}, \text { w }}$ values of plasminogens $A$ and $B$ under various conditions. - , Plasminogen $B$ at $\mathrm{pH} 7 \cdot 6 ; \Delta$, plasminogen $B$ at $\mathrm{pH} 7.6$ in $2 \mathrm{M}$-urea; $\times$, plasminogen $B$ at $\mathrm{pH} 7 \cdot 6$ with $\epsilon$-aminohexanoic acid $(10 \mathrm{~mm}) ; \square$, plasminogen $B$ at pH 2.0 ; $\bigcirc$, plasminogen $A$ at $\mathrm{pH} 7.6$ with $\epsilon$-aminohexanoic acid (10 mM); $\triangle$, plasminogen $A$ at $\mathrm{pH} 7.6$ in $2 \mathrm{M}$-urea; $\square$, plasminogen $A$ at $\mathrm{pH} 2.0 ;+$, plasminogen $A$ at $\mathrm{pH} 2.0$ with $\epsilon$-aminohexanoic acid $(10 \mathrm{~mm})$. 
coefficient did not show the customary dependence on protein concentration, the calculated regression line being:

$$
S=4 \cdot 90+0 \cdot 08 c
$$

where $c$ is expressed as $\mathrm{g} . / 100 \mathrm{ml}$. This relationship was confirmed by a differential sedimentation study, with the synthetic-boundary cell (Schachman, 1959) and two plasminogen concentrations, respectively 5 and $10 \mathrm{mg} . / \mathrm{ml}$., an $S_{20, w}$ value of $4.91 \mathrm{~s}$ being calculated for this experiment. Moreover, an increase of the plasminogen concentration to $25 \mathrm{mg}$. $/ \mathrm{ml}$., as compared with the maximum concentration of $10 \mathrm{mg} . / \mathrm{ml}$. illustrated in Fig. 5, gave an $S_{20, w}$ value of $5 \cdot 09 \mathrm{~s}$, confirming the validity of the calculated regression line.

The ultracentrifugal results, except in two runs, were obtained with plasminogen $(B)$ prepared by method 2; the other two determinations, which fitted perfectly on the calculated regression line (not distinguished separately in Fig. $5 b$ ) were made with material (kindly supplied by Dr Hink, Cutter Laboratories, Calif., U.S.A.) prepared by the method of Hink \& MacDonald (1962), in which $\epsilon$-aminohexanoic acid is also employed during a preparative step.

Three ultracentrifugal runs were also performed, at neutral $\mathrm{pH}$, with plasminogen $(B)$ prepared by method 1 , in which the use of $\epsilon$-aminohexanoic acid fractionation had been avoided. Owing to shortage of material, the runs were made at protein concentrations that did not permit adequate evaluation of the patterns for heterogeneity, but the findings are probably valid since the specific activities of plasminogen preparations $A$ and $B$ were comparable. In each run the $S_{20, w}$ value exceeded the $4.9 \mathrm{~s}$ calculated for plasminogen preparation $B$, and the highest value obtained was $6 \cdot 0 \mathrm{~s}$.

Plasminogen $A$ may be dissolved at neutral $\mathrm{pH}$ by the use of concentrated urea solutions (2-5M) without loss of biochemical activity. Fig. 5 demonstrates that the sedimentation behaviour of plasminogen $A$ dissolved in this manner was indistinguishable from that of plasminogen $B$ : a representative run is shown in Fig. $6(b)$.

(b) Ultracentrifugation at $\mathrm{pH} 2$. Plasminogen $B$ preparations, when adjusted to $\mathrm{pH} 2 \cdot 0$, acquire solubility properties similar to those of plasminogen $A$, and this alteration cannot be reversed by further $\mathrm{pH}$ adjustment; the change in solubility appears almost instantaneously if the $\mathrm{pH}$ is lowered below a critical value of approx. 4.5. Fig. 5(b) shows sedimentation data as a function of protein concentration for both plasminogen $B$, taken to $\mathrm{pH} 2 \cdot 0$, and for plasminogen $A$ examined at this pH. The results from both sets of experiments fit the same regression line, which exhibits a high degree of dependence of sedimentation coefficient on protein con- centration. The $S_{20, w}^{0}$ value was $4 \cdot 28 \mathrm{~s}$ and the equation for the regression line:

$$
S=4 \cdot 28-0 \cdot 43 c
$$

where $c$ is expressed as g./100 ml. Photographs of representative runs for both preparations are shown in Figs. 6(e) and 6(f); both are single peaks, and noteworthy is the narrowing and sharpening of the plasminogen $B$ peak run at $\mathrm{pH} 2.0$ as compared with that run at $\mathrm{pH} 7 \cdot 6$ (Figs. $6 a$ and $6 e$ ).

(c) Effect of $\epsilon$-aminohexanoic acid on sedimentation behaviour. Plasminogen $A$ may be dissolved in neutral buffers containing $\epsilon$-aminohexanoic acid (10 mM). Fig. 5(a) shows sedimentation as a function of protein concentration for both plasminogen $A$ and acid-treated plasminogen $B$ examined in

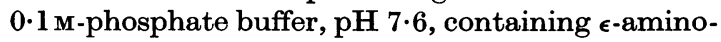
hexanoic acid $(10 \mathrm{~mm})$. These preparations were indistinguishable on ultracentrifugal examination in Fig. 5(a), and the regression line, fitting both sets of results, was virtually independent of protein

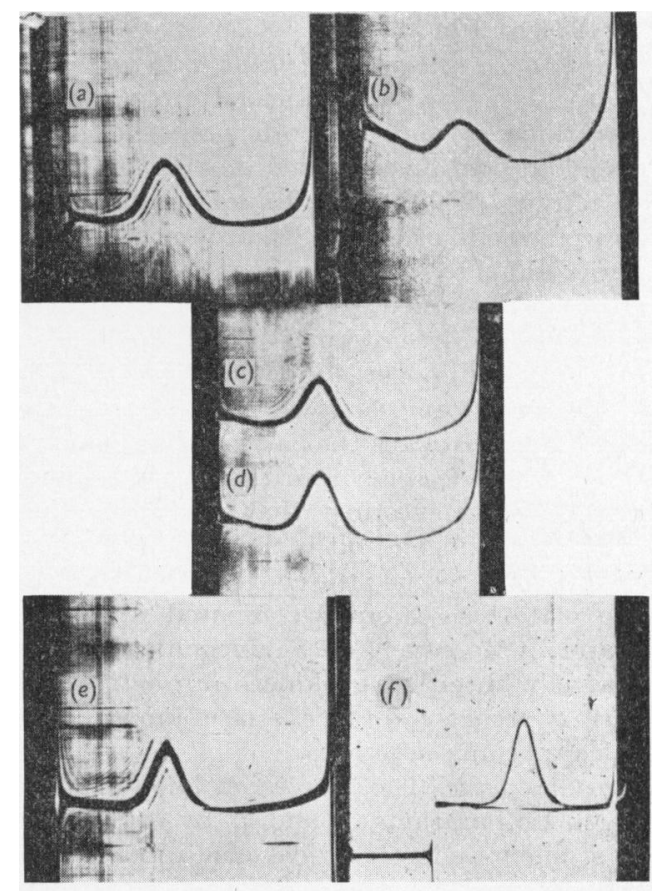

Fig. 6. Representative run patterns of plasminogen under various conditions. All patterns were obtained after $80 \mathrm{~min}$. at $59780 \mathrm{rev} . / \mathrm{min}$. except $(f)$ where the speed was $52640 \mathrm{rev} . / \mathrm{min}$. (a) Plasminogen $B, 10 \mathrm{mg} . / \mathrm{ml}$., at $\mathrm{pH} \mathrm{7 \cdot 6 \text {; }}$ (b) plasminogen $A, 6 \mathrm{mg} . / \mathrm{ml}$, at $\mathrm{pH} 7.6$ in $2 \mathrm{M}$-urea; (c) plasminogen $B, 10 \mathrm{mg} . / \mathrm{ml}$, at $\mathrm{pH} 7.6 \mathrm{with} \epsilon$-aminohexanoic acid (10 mM); (d) plasminogen $A, 10 \mathrm{mg} . / \mathrm{ml}$, at pH 7.6 with $\epsilon$-aminohexanoic acid $(10 \mathrm{~mm})$; (e) plasminogen $B, 7 \mathrm{mg}$./ ml., at $\mathrm{pH} 2 \cdot 0 ;(f)$ plasminogen $A, 10 \mathrm{mg} . / \mathrm{ml}$., at $\mathrm{pH} 2 \cdot 0$. 
concentration. The $S_{20, \text { w }}^{0}$ value (Fig. $5 a$ ) was $4 \cdot 29 \mathrm{~s}$ and the slope of the line:

$$
S=4 \cdot 29+0 \cdot 002 c
$$

where $c$ is expressed as $\mathrm{g} . / 100 \mathrm{ml}$. As shown in Fig. $5(b)$ this constant $4 \cdot 29$ is the same as that $(4 \cdot 28)$ obtained by examination of plasminogen at $\mathrm{pH} 2 \cdot 0$, but differs significantly from that $(4 \cdot 90)$ of plasminogen $B$ examined at neutral $\mathrm{pH}$.

Control experiments in which plasminogen $B$, never exposed to acid conditions, was examined in 0.1 M-phosphate buffer, pH 7.6, containing $\epsilon$ aminohexanoic acid (10 $\mathrm{mm})$, yielded significant findings. These are shown $(x)$ in Fig. 5(a), where the $S$ values, instead of fitting the top regression line for plasminogen $B$ at neutral $\mathrm{pH}$, fit the lower regression line for plasminogen $A$ dissolved in $\epsilon$-aminohexanoic acid. Thus the addition of $\epsilon$ aminohexanoic acid (10 $\mathrm{mm})$ to plasminogen $B$ in neutral buffer alters the $S_{20 \text {,w }}^{0}$ value from 4.90 to $4 \cdot 29 \mathrm{~s}$.

Significantly $\epsilon$-aminohexanoic acid (10 mM) added to plasminogen $A$ at $\mathrm{pH} 2.0$ did not alter its sedimentation behaviour (Fig. $5 b$ ); but $\epsilon$-aminohexanoic acid (10 $\mathrm{mm})$ added to plasminogen $A$, which had been dissolved at neutral $\mathrm{pH}$ in $5 \mathrm{~m}$-urea, decreased the $S$ value from $4 \cdot 9$ to $4 \cdot 3 \mathrm{~s}$.

Analysis of ultracentrifugal patterns. The apparent diffusion coefficients of both types of plasminogen at neutral $\mathrm{pH}$ increased with time. The values calculated for three concentrations of plasminogen preparation $B(26,10$ and $6 \mathrm{mg} . / \mathrm{ml}$.) at neutral $\mathrm{pH}$ in the absence of $\epsilon$-aminohexanoic acid at $50 \mathrm{~min}$. were respectively $9.85 \times 10^{-7}, 10.8 \times 10^{-7}$ and $8.4 \times 10^{-7} \mathrm{~cm}^{2}$ sec. $^{-1}$ and at $100 \mathrm{~min} .13 .0 \times 10^{-7}$, $12.5 \times 10^{-7}$ and $11.9 \times 10^{-7} \mathrm{cm.}^{2} \mathrm{sec}^{-1}$. Plasminogen preparations $A$ and $B$ dissolved in $0 \cdot 1 \mathrm{M}$-phosphate buffer containing $\epsilon$-aminohexanoic acid ( $10 \mathrm{~mm}$ ) at concentrations of 6 and $6.5 \mathrm{mg} . / \mathrm{ml}$. had apparent diffusion coefficients at $50 \mathrm{~min}$. of $5 \cdot 8 \times 10^{-7}$ and $6 \cdot 0 \times 10^{-7} \mathrm{~cm}^{2} \mathrm{sec}^{-1}$ and at $100 \mathrm{~min}$. $7 \cdot 8 \times 10^{-7}$ and $8.6 \times 10^{-7} \mathrm{~cm}^{2}$ sec. $^{-1}$.

The apparent diffusion coefficient for plasminogen $A$ at $\mathrm{pH} 2 \cdot 0$ was calculated from several runs over a concentration range of 4-12 mg./ml.; in all runs $A^{2} / H^{2}$ was linearly related to time. The respective values for 12,8 and $4 \mathrm{mg} . / \mathrm{ml}$. were $2 \cdot 54 \times 10^{-7}, 2 \cdot 31 \times 10^{-7}$ and $4 \cdot 12 \times 10^{-7} \mathrm{~cm}^{2}$ sec. ${ }^{-1}$. These findings suggest that plasminogen at $\mathrm{pH} 2 \cdot 0$ shows the least, plasminogen in $\epsilon$-aminohexanoic acid a much greater and plasminogen at neutral $\mathrm{pH}$ in the absence of $\epsilon$-aminohexanoic acid the greatest tendency towards heterogeneity in sedimentation rate.

Concentration-dependence of $\epsilon$-aminohexanoic acid action on plasminogen. Samples of plasminogen $A$ [approx. 0.1 mM; assumed mol.wt. 100000 (Shulman et al. 1958; Davies \& Englert, 1960)] were equilibrated for $1.5 \mathrm{hr}$. with $0.05 \mathrm{M}$-phosphate buffer, $\mathrm{pH} 7 \cdot 6$, containing $\epsilon$-aminohexanoic acid in concentrations that ranged from $10 \mathrm{~mm}$ to 0 . The solubilizing action of buffer containing $\epsilon$-aminohexanoic acid at a concentration of $10 \mu \mathrm{M}$ was only just detectable $(0.1 \mathrm{mg} . / \mathrm{ml}$.), whereas the use of buffer containing it at a concentration of $0.1 \mathrm{~mm}$ yielded a fourfold increase of solubility $(0.3 \mathrm{mg} . /$ ml.) over control values. However, $1 \mathrm{mm- \epsilon}$-aminohexanoic acid produced a 50 -fold $(3.5 \mathrm{mg} . / \mathrm{ml}$.) and $10 \mathrm{~mm}$ - $\epsilon$-aminohexanoic acid a 110-fold increase of plasminogen solubility $(7 \cdot 75 \mathrm{mg} . / \mathrm{ml}$.) over control values.

The influence of the concentration of e-aminohexanoic acid on sedimentation behaviour was examined by dissolving plasminogen $A$ in $10 \mathrm{mN}$ hydrochloric acid and plasminogen $B$ in $0 \cdot 1 \mathrm{M}$-phosphate buffer, $\mathrm{pH} \mathbf{7 \cdot 6}$, both at a concentration of $10 \mathrm{mg} . / \mathrm{ml}$. (approx. $0.1 \mathrm{~mm}$-plasminogen), and dialysing samples of both preparations for $48 \mathrm{hr}$. against $0 \cdot 1 \mathrm{M}$-sodium dihydrogen phosphate adjusted to $\mathrm{pH} 7 \cdot 6$ with $\mathrm{N}$-sodium hydroxide and containing $\epsilon$-aminohexanoic acid at concentrations ranging from $10 \mathrm{~mm}$ to $10 \mu \mathrm{M}$. Supernatants were assayed for protein measured as tyrosine equiv. (histogram in Fig. 7) and examined in the ultracentrifuge.

After equilibration with buffer containing $\epsilon-$ aminohexanoic acid at a concentration of $10 \mathrm{~mm}$, plasminogen $A$ was completely dissolved, and it and its companion plasminogen $B$ sample both had a sedimentation coefficient of $4 \cdot 21 \mathrm{~s}$. After equilibration with $1 \mathrm{~mm}$ - $\epsilon$-aminohexanoic acid, the plasminogen $A$ supernatant was assayed at $7.5 \mathrm{mg}$.

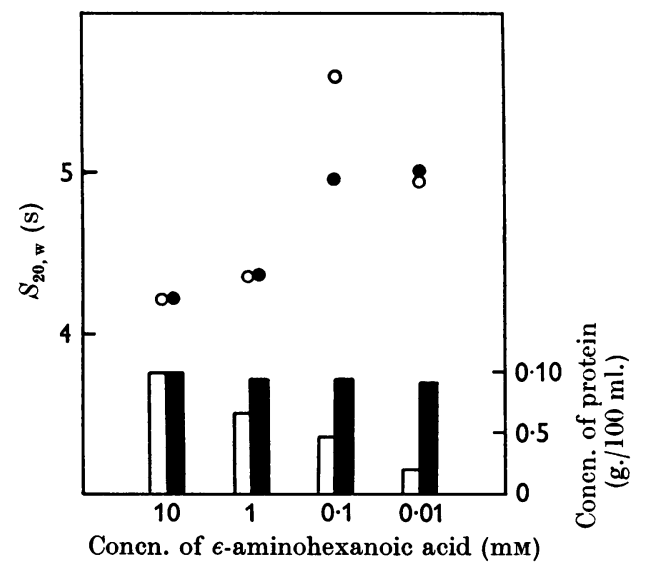

Fig. 7. Plasminogen $A(10 \mathrm{mg} . / \mathrm{ml}$. of $0.01 \mathrm{~N}-\mathrm{HCl})$ and plasminogen $B(10 \mathrm{mg} . / \mathrm{ml}$. of phosphate buffer, $\mathrm{pH} \mathbf{7 \cdot 6})$ dialysed for $48 \mathrm{hr}$. against phosphate buffer, $\mathrm{pH} 7 \cdot 6$, containing $\epsilon$-aminohexanoic acid at the concentrations shown. The Figure shows protein concentration $(\square)$ and $S_{20 . w}(\bigcirc)$ for plasminogen $A$, and protein concentration ( $\square$ ) and $S_{20 \text {, w }}$ (O) for plasminogen $B$.

Bioch. 1964, 93 
of protein $/ \mathrm{ml}$., and both it and plasminogen $B$ had sedimentation coefficients of $4 \cdot 31 \mathrm{~s}$. However, at $0.1 \mathrm{~mm}$ - $\epsilon$-aminohexanoic acid plasminogen $A$ was only solubilized to the extent of $4 \mathrm{mg} . / \mathrm{ml}$. and its sedimentation coefficient was $5 \cdot 7 \mathrm{~s}$ compared with $4.9 \mathrm{~s}$ for that of the plasminogen $B$ sample. In contrast, at $10 \mu \mathrm{M}-\epsilon$-aminohexanoic acid, where plasminogen $A$ was only solubilized to the extent of $2 \mathrm{mg} . / \mathrm{ml}$., both it and the plasminogen preparation $B$ showed respective sedimentation coefficients of 4.95 and $5.0 \mathrm{~s}$. These findings were confirmed in a further experiment where plasminogen preparations $A$ and $B$, both at $10 \mathrm{mg} . / \mathrm{ml}$. in $0.1 \mathrm{M}$-phosphate buffer, pH $7 \cdot 6$, containing $\epsilon$-aminohexanoic acid (10 $\mathrm{mm})$, were dialysed against two changes of this buffer without $\epsilon$-aminohexanoic acid (500 vol.). After dialysis for $24 \mathrm{hr}$., the sedimentation coefficient for plasminogen $A$ was $4.91 \mathrm{~s}$ and that for the plasminogen $B 4 \cdot 25 \mathrm{~s}$; whereas, after dialysis for $48 \mathrm{hr}$., the respective $S_{20 \text {,w }}$ values were $5 \cdot 60$ and $5 \cdot 08 \mathrm{~s}$.

These findings indicated that the action of $\epsilon$-aminohexanoic acid in altering the sedimentation behaviour of either plasminogen was in part reversible and required a critical $\epsilon$-aminohexanoic acid concentration, i.e. approx. $10 \epsilon$-aminohexanoic acid molecules/molecule of plasminogen, for its action. Moreover, the solubilizing action of $\epsilon$-aminohexanoic acid on plasminogen $A$ was partially operative below the critical concentration required for alteration of molecular sedimentation behaviour.

Electrophoretic properties. Plasminogen $B$ was examined by free-boundary (classical) electrophoresis in buffers of ionic strength $0 \cdot 1$, and mobility determinations (mean values from both limbs), expressed in $10^{-5} \times \mathrm{cm}^{2} \mathrm{v}^{-1}$ sec. ${ }^{-1}$, made respectively at $\mathrm{pH} 4 \cdot 0,7 \cdot 0,7 \cdot 6$ and $8 \cdot 6$, are plotted in Fig. 8 as a function of pH. Fig. 8 also includes results obtained by Shulman et al. (1958) on the electrophoretic properties of acid-purified plasminogen. There is excellent agreement between the two sets of results at $\mathrm{pH} 4 \cdot 0$ and $8 \cdot 6$, but some discrepancy between the present and previous findings at neutral $\mathrm{pH}$; indeed, even with the present highly soluble plasminogen $B$ preparations, difficulties were encountered during electrophoretic examination at neutral $\mathrm{pH}$. Though plasminogen was in clear solution at the start of electrophoresis (after dialysis for $24 \mathrm{hr}$. against electrophoretic buffer), the solution tended to develop a degree of opacity 1-2 $\mathrm{hr}$. after commencing the run with consequent partial obscuring of the pattern. Though mobility determinations were still possible, later pattern photographs were of unsatisfactory quality, and for this reason the pattern photographs of plasminogen $B$, at neutral pH (Fig. $9 e$ ), are those taken after $45 \mathrm{~min}$. Though the ascending limb shows a small faster component, the main peak is relatively sharp, but the descending limb photograph shows considerable heterogeneity.

The addition of $\epsilon$-aminohexanoic acid $(10 \mathrm{~mm})$ to plasminogen $B$, prepared for electrophoresis in phosphate buffer, $\mathrm{pH} 7 \cdot 6$ and $I 0 \cdot 1$, caused significant changes in the electrophoretic behaviour of the protein, and these findings are illustrated in Figs. 8 and 9 . Though the addition of $\epsilon$-aminohexanoic acid to the buffer caused only negligible alteration in buffer conductivity, the mobility of the plasminogen peak, in buffer containing $\epsilon$-aminohexanoic acid, was $1.23 \times 10^{-5} \mathrm{~cm}^{2} \mathrm{v}^{-1}$ sec. $^{-1}$ compared with $2.43 \times 10^{-5} \mathrm{~cm}^{2} \mathrm{v}^{-1}$ sec. $^{-1}$ for plasminogen in identical buffer without $\epsilon$-aminohexanoic acid. The patterns (Figs. $9 a$ and $9 b$ ) exhibited, especially in the descending limbs, a smaller degree of heterogeneity than those shown by plasminogen in the absence of $\epsilon$-aminohexanoic acid, the solutions remained clear through the electrophoretic run and the later patterns (260 min.) show evidence of small fast-running components.

Plasminogen $A$ solubilized by $\epsilon$-aminohexanoic acid in neutral electrophoretic buffer had a similar

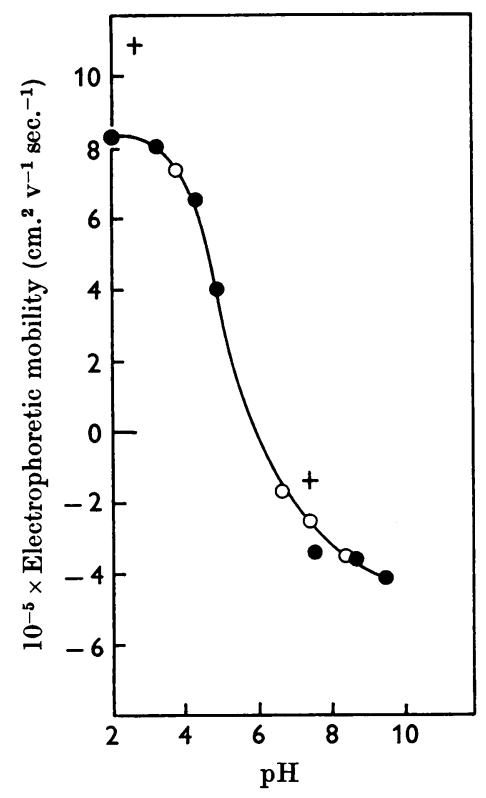

Fig. 8. Free-boundary electrophoretic studies on plasminogen, showing electrophoretic mobility as a function of $\mathrm{pH}$. Determinations with plasminogen $B(O)$ and plasminogen $A$ (O) fitted a pH-dependent curve, but the addition of e-aminohexanoic acid $(+)$ above the isoelectric point decreased mobility and below it caused increased mobility. Protein concentrations ranged from 6 to $15 \mathrm{mg} . / \mathrm{ml}$. except in the studies of plasminogen $A$ at near neutral $\mathrm{pH}$ in the absence of $\epsilon$-aminohexanoic acid, where the concentrations were very small owing to the poor solubility. 


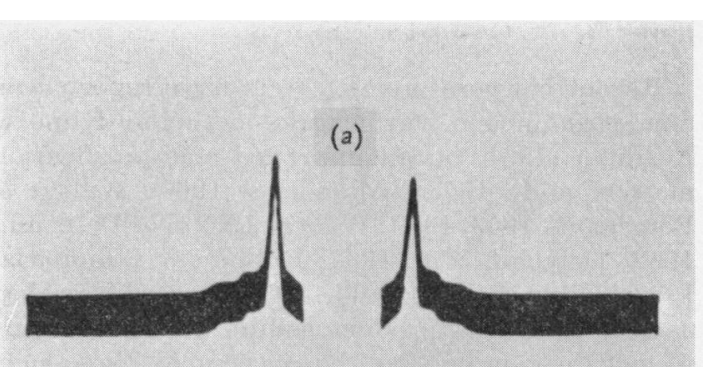

(b)

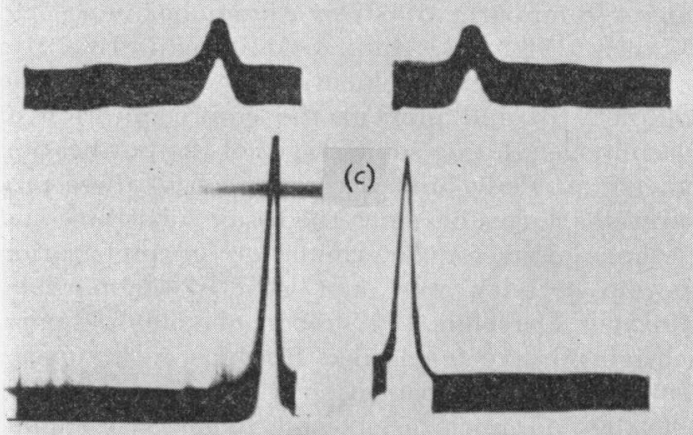

(d)

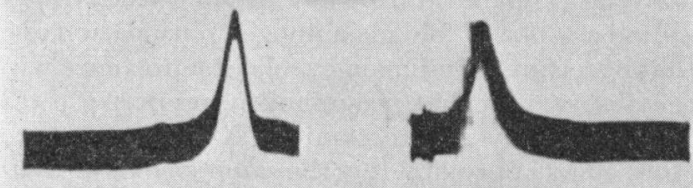

(e)

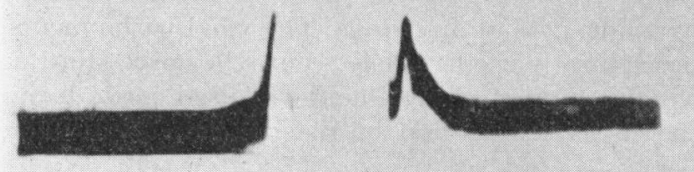

Fig. 9. Electrophoretic patterns of plasminogens $A$ and $B$. (a) Plasminogen $B$ in phosphate buffer, $\mathrm{pH} 7 \cdot 6$, containing $\epsilon$-aminohexanoic acid (10 $\mathrm{mM})$, after $65 \mathrm{~min}$.; $(b)$ as for $(a)$ but after 260 min.; (c) plasminogen $A$ at $\mathrm{pH} 7.6$ with $\epsilon$-aminohexanoic acid (10 mM) after $90 \mathrm{~min}$; $(d)$ as for $(c)$ but after 240 min.; (e) plasminogen $B$ in phosphate buffer, $\mathrm{pH} 7 \cdot 6$, after $45 \mathrm{~min}$. Left: descending; right: ascending.

mobility, $1.21 \times 10^{-5} \mathrm{~cm}^{2} \mathrm{v}^{-1}$ sec. ${ }^{-1}$, to that of plasminogen $B$ in neutral buffer containing $\epsilon$ aminohexanoic acid. The pattern photographs for these two preparations (Figs. $9 c$ and $9 d$ ) were similar and plasminogen $A$ showed, as did plasminogen $B$ dissolved in buffer containing $\epsilon$-aminohexanoic acid, small fast-running components moving ahead of the main peak. Plasminogen $A$ solutions in buffer containing $\epsilon$-aminohexanoic acid remained visually clear during electrophoresis.

Though the addition of $\epsilon$-aminohexanoic acid to plasminogen at a $\mathrm{pH}$ well above its isoelectric point produces a significant decrease in electrophoretic mobility, the opposite action was encountered when $\epsilon$-aminohexanoic acid was added to plasminogen at a $\mathrm{pH}$ well below the protein isoelectric point. This is shown in Fig. 8, where the addition of $\epsilon$ aminohexanoic acid (10 mM) to plasminogen $A$ at pH 2.0 induced a significant increase of electrophoretic mobility from $8 \cdot 1 \times 10^{-5}$ to $10^{-4} \mathrm{~cm}^{2} \mathrm{v}^{-1}$ sec. ${ }^{-1}$.

Gel electrophoresis in polyacrylamide gel. Plasminogen $B$, in tris-glycine buffer at $\mathrm{pH} 8 \cdot 1$, was examined by zone electrophoresis in polyacrylamide gels. In each instance two gels were used, one of which was stained for protein localization and another cut into $5 \mathrm{~mm}$. slices; after freezing, grinding and thawing, each individual slice was eluted into buffer. Each buffer eluate was assayed for plasminogen activity by a micro casein assay, and specific activity calculated after tyrosine assay.

The results from two representative gel runs, conducted simultaneously under the same electrophoretic conditions, are shown in Fig. 10(a) (run made in $15 \%$ gel) and in Fig. 10(b) (run made in $7 \cdot 5 \%$ gel). Not all the applied protein passed into the gel and there was probably some additional loss during the elution stage: in this experiment total plasminogen eluate activity was $60 \%$ of that originally used for the $15 \%$ gel, and $75 \%$ for the $7.5 \%$ gel. Both gels displayed at least four stained bands (poorly reproduced in Fig. 10) and all eluates, corresponding to the stained bands, exhibited caseinolytic activity after activation with streptokinase or urokinase.

Calculation of specific activity for the individual

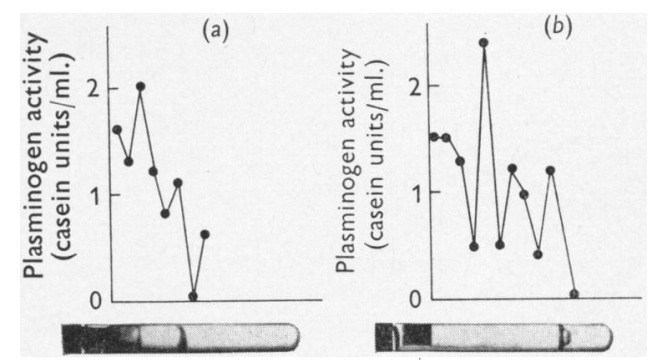

Fig. 10. Polyacrylamide-gel electrophoresis on plasminogen $B$ at pH 8.1: $(a)$ gel concentration $15 \%$; $(b)$ gel concentration $\mathbf{7 . 5} \%$. Plasminogen contents of eluates of $5 \mathrm{~mm}$. gel slices are shown against migration distance. All stained areas (poorly displayed in the photographs) contained plasminogen. The plasminogen was activated by $(a)$ streptokinase and $(b)$ urokinase. 
gel eluates was hindered by the small volumes, low plasminogen concentrations of the eluates and the presence of a small blank reading from gel slices. However, the mean specific activity values in the gel eluates from six comparable runs suggested that the specific activity had not been decreased by electrophoresis and that all eluates containing plasminogen were of similar specific activity. The run on $\mathbf{7 . 5} \%$ gel showed higher electrophoretic mobility for the individual components and more complete resolution of each component, indicating that molecular sieving in the polyacrylamide gel had exerted an important influence in ensuring separation during the electrophoretic run. This finding, in conjunction with the findings on the specific activity in gel eluates, suggests that the separate stained bands in the gels may represent different plasminogen polymers rather than discrete electrophoretic entities.

Gel-electrophoretic examination of plasminogen preparations $A$ and $B$ in buffers containing $\epsilon$ aminohexanoic acid (10 $\mathrm{mm}$ ) showed only two stainable bands. Both preparations showed a welldefined heavily stained band of low mobility, indistinguishable in the two cases, but the faintly stained band of faster mobility moved further in the plasminogen $B$ gel than in the plasminogen $A$ gel; this finding of diminished gel-electrophoretic mobility of plasminogen in the presence of $\epsilon$-aminohexanoic acid is comparable with the free electrophoretic results. In each the major portion of plasminogen was located in the slow-moving bands but, though slight activity was detected in the highmobility band of plasminogen $B$ material, none was found in that of plasminogen $A$.

Immunoelectrophoretic studies. Fig. 11 displays a representative immunoelectrophoretic study, in agar, of plasminogen, purified by method 2 before the chromatographic step (top of Fig. 11) and after chromatographic fractionation (bottom of Fig. 11) run against a rabbit anti-(human fraction III) serum. Several precipitin lines developed between the non-chromatographed plasminogen preparation and the antiserum, but only two such lines against the final purified product. Since these latter lines appear to blend rather than cross, they may represent a reaction of identity and indicate that, on electrophoresis, the preparation has been separated into plasminogen and plasminogen aggregates. This hypothesis was supported by electrophoresis of plasminogen $B$ in polyacrylamide gel by the technique described in the preceding section : the gel was then mounted on an agar slide opposite an antiserum trough. Only a single precipitin line, its parts showing the reaction of identity, was observed, which extended to cover the entire area, representing the previously defined distinct stained band region of the gel.

\section{DISCUSSION}

Recently several investigators have reported on new plasminogen purification methods: Kline \& Fishman (1961) on an improved acid-purification method and others (Alkjaersig, 1960; Wallen \& Bergström, 1959, 1960; Wallen, 1962 $a$, $b$; Derechin, 1962; Derechin et al. 1962; Robbins \& Summaria, 1963; Hink \& McDonald, 1962) procedures that usually yielded a product soluble at neutral $\mathrm{pH}$. A feature common to the success of these new methods has been the use of certain basic amino acids, lysine (Kline \& Fishman, 1961; Hagan et al. 1960; Derechin, 1962; Derechin et al. 1962; Robbins \& Summaria, 1963) or $\epsilon$-aminohexanoic acid (Wallen, 1962a, b; Hink \& McDonald, 1962), in buffers as selective eluents or to enhance the solubility of and prevent the co-precipitation of plasminogen during some stages of the purification procedure. Only limited comparison of these preparations is feasible since the assay substrates and methods used for determination of preparation specific activity were not strictly comparable. However, Derechin (1962) reported a 500-fold purification relative to plasma, Robbins \& Summaria (1963) a 900-fold purification, Hagan et al. (1960) a 300-400-fold purification and Kline \& Fishman (1961) a 400-fold purification relative to serum. Material prepared during the present study represented a 400-500-fold plasminogen purification over that of serum, a finding in excellent agreement with the observation that plasminogen, prepared in this Laboratory by the method of Kline \& Fishman (1961), had approximately the same specific activity as the present preparations. The present purification procedures strictly avoid extremes of $\mathrm{pH}$ change, nor does the first procedure utilize $\epsilon$-aminohexanoic acid at any stage. The yield with our first procedure varied widely, but the procedure in which $\epsilon$-aminohexanoic acid was used early during the initial extraction of plasminogen from Cohn

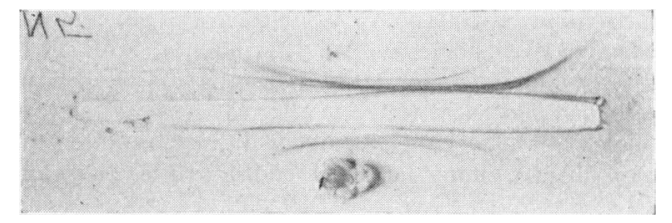

Fig. 11. Agar-gel electrophoresis of plasminogen obtained by method 2 before application to the column (top of slide) and after passage through the column (bottom of slide) diffused against rabbit anti-(human fraction III) serum (contained in centre trough). Several extraneous components (precipitin lines) were eliminated from the preparation by column chromatography. 
plasma fraction III proved to be highly reproducible both with respect to yield and purity of the final product.

The properties of plasminogen $B$, prepared by the present chromatographic techniques, both differ in some respects from and are similar in others to those of plasminogen $A$. The most striking differences between the two types of preparation are manifested by the high solubility and relative stability of the present preparations, at neutral $\mathrm{pH}$, compared with the virtual insolubility and extreme instability of the acid-purified preparations under these conditions. Moreover, plasminogen prepared by these two different methods exhibited significant differences in sedimentation behaviour. Whereas the $S_{20, w}^{0}$ value for plasminogen $A$ material was $4 \cdot 3 \mathrm{~s}$ and showed a clear dependence of $S$ on protein concentration, the comparable $S$ value for plasminogen $B$ was $4.9 \mathrm{~s}$ and this value was virtually independent of protein concentration. On the other hand there are important similarities: both types of preparation possessed approximately the same specific activity; both display similar activation kinetics with streptokinase: both have similar proactivator: plasminogen ratios; both, as far as comparison is feasible by free-boundary electrophoresis for proteins of such dissimilar solubility properties, exhibit an identical electrophoretic mobility. Further, the plasminogen $B$ preparations, which have never been exposed to a $\mathrm{pH}$ below $5 \cdot 2$, can be easily converted by brief treatment at acid $\mathrm{pH}$ into a protein indistinguishable from plasminogen $A$.

The essential similarity and relationship of these two plasminogen preparations, despite the points of difference discussed above, is demonstrated by the findings obtained after the addition of $\epsilon$-aminohexanoic acid to both. Though the addition of $\epsilon$-aminohexanoic acid to plasminogen $A$ profoundly alters its properties, particularly those pertaining to solubility characteristics, its addition to plasminogen $B$ exerts no obvious gross alteration in properties, but the two preparations, in $10 \mathrm{~mm}-\epsilon-$ aminohexanoic acid, besides showing similar solubility characteristics, now exhibit similar sedimentation and electrophoretic behaviour, which in each instance differs significantly from that of the parent protein. Differences in the sedimentation behaviour of plasminogen $B$ consist in a fall of $S_{20, w}^{0}$ from 4.9 to $4 \cdot 3 \mathrm{~s}$, but without alteration of the previous independence of $S$ on protein concentration. In contrast the addition of $\epsilon$-aminohexanoic acid to plasminogen $A$ at $\mathrm{pH} 2.0$ alters neither the $S_{20 \text {,w }}^{0}$ value of $4.3 \mathrm{~s}$ nor the dependence of $S$ values on protein concentration; at neutral $\mathrm{pH}$, though the $S_{20, \text { w }}^{0}$ value is unaltered, the dependence of $S$ on protein concentration is abolished. $\epsilon$-Aminohexanoic acid produces identical effects on electro- phoretic mobility with both types of preparation, resulting in significantly decreased mobility above the isoelectric point and significantly increased mobility below it.

Much recent work, reviewed by LinderstrømLang \& Schellman (1959), has emphasized the plasticity of protein secondary and tertiary structure and the high probability that all proteins showing readily reversible transformations undergo appreciable variations in structure. The present results, especially the ultracentrifugal findings, would be entirely consistent with, and, indeed, would suggest that wholly or partially reversible changes of plasminogen structure underlie, variations in its properties. Disruption of protein tertiary structure by extreme $\mathrm{pH}$ change is a recognized phenomenon and the properties of acid-purified or acid-treated plasminogen could be explained by postulating such a structural disturbance, which is unaffected by simple reversion of the $\mathrm{pH}$ to neutral or alkaline ranges. In this way the changed solubility and sedimentation properties would be accounted for, with preservation of the other molecular parameters. The known characteristics of acid $\mathrm{pH}$ action on the molecule would be entirely consistent with this hypothesis as: (1) the whole molecule is involved in the change as evidence of molecular cleavage by acid action is lacking; (2) there is a single defined critical $\mathrm{pH}$ at which the molecular alteration, defining solubility or insolubility at neutral $\mathrm{pH}$, occurs : time of exposure to acid $\mathrm{pH}$ has not been demonstrated to be a factor of significance, and plasminogen preparations exhibiting an intermediate degree of solubility between plasminogen preparations $A$ and $B$ have not been prepared; (3) acid treatment of plasminogen does not result in loss of biochemical activity, and the stability of the product, stored at $\mathrm{pH} \mathrm{2,} \mathrm{is} \mathrm{extremely} \mathrm{high} \mathrm{(months} \mathrm{or}$ years without deterioration): consequently the action of acid on plasminogen, though profoundly altering its solubility properties and sedimentation behaviour, is not that of a denaturant, at least in the sense that the word is normally understood; (4) the concept of protein structural alteration in the presence of acid is supported by the instability of plasminogen $A$ at neutral pH, compared with that of plasminogen $B$ never exposed to a pH below $5 \cdot 2$; (5) the finding that plasminogen $A$ may, after treatment with $\epsilon$-aminohexanoic acid and subsequent dialysis, acquire sedimentation characteristics similar to those of plasminogen $B$, indicates that the action of acid on the plasminogen molecule is potentially at least a partially reversible one.

Similarly, the alteration in biophysical parameters, sedimentation behaviour and electrophoretic mobility observed when plasminogen $B$ was treated with $\epsilon$-aminohexanoic acid would also be explicable on the hypothesis that interaction of 
$\epsilon$-aminohexanoic acid and plasminogen resulted in structural alterations, of a reversible nature, in protein secondary or tertiary folding. The finding that these biophysical parameters reverted to their original values on removal of the $\epsilon$-aminohexanoic acid by dialysis would be confirmatory, especially since this reversion is sufficiently slow to suggest $\epsilon$-aminohexanoic acid-protein interaction. Also significant in this regard is the finding that only 10 molecules of $\epsilon$-aminohexanoic acid/molecule of plasminogen were sufficient to induce the full effect; since the sedimentation constant was not altered when $\epsilon$-aminohexanoic acid and plasminogen were present in equimolar concentrations it is probable that more than a single $\epsilon$-aminohexanoic acid molecule is required to alter protein structure in any significant manner. Alkjaersig et al. (1959b) demonstrated that where plasminogen concentration was approx. $0 \cdot 1 \mathrm{~mm}$, an $\epsilon$-aminohexanoic acid concentration exceeding $1 \mathrm{~mm}$ was required to inhibit, to any significant degree, plasminogen activation by urokinase or streptokinase: an $\epsilon$-aminohexanoic acid concentration now demonstrated to decrease the sedimentation constant of plasminogen $B(0.1 \mathrm{mM})$ from 4.9 to $4.3 \mathrm{~s}$. This finding suggests that actual alteration of plasminogen structure may underlie the effectiveness of $\epsilon$-aminohexanoic acid as an inhibitor of plasminogen activation.

\section{SUMMARY}

1. Two methods for the purification of human plasminogen from the euglobulin fraction of serum or from Cohn human-plasma fraction III, differing essentially by the use of $\epsilon$-aminohexanoic acid in one but not in the other procedure, have been described. Both preparations were of specific activity comparable with that of plasminogen prepared by acid-purification procedures, but differed from these latter preparations with respect to their stability and solubility at neutral $\mathrm{pH}$.

2. Biophysical examination of these preparations, acid-purified plasminogen $(A)$ and plasminogen of both types $(A$ and $B)$ in the presence of $\epsilon$-aminohexanoic acid, revealed that, according to its method of preparation and treatment, plasminogen might exhibit one of three types of ultracentrifugal or one of two types of electrophoretic behaviour. Interconversion of these plasminogen types, by appropriate treatment of the preparations, was demonstrated, and it was concluded that the plasminogen molecule exhibits unusual plasticity, differences in various preparation properties being related to wholly or partially reversible structural changes.

It is a pleasure to acknowledge my indebtedness to my colleagues, Dr Sol Sherry and Dr Anthony P. Fletcher, for many stimulating discussions and suggestions; Mr Larry
Mattler and Mrs Odessa Turner provided excellent technical assistance. This work was supported by a grant (no. H-3745) from the National Heart Institute, U.S. Public Health Service, Bethesda, Md.

\section{REFERENCES}

Alkjaersig, N. (1960). Fed. Proc. 19, 58.

Alkjaersig, N., Fletcher, A. P. \& Sherry, S. (1958a). J.biol. Chem. 233, 81.

Alkjaersig, N., Fletcher, A. P. \& Sherry, S. (1958b). J. biol. Chem. 233, 86.

Alkjaersig, N., Fletcher, A. P. \& Sherry, S. (1959a). J.clin. Invest. 38, 1086.

Alkjaersig, N., Fletcher, A. P. \& Sherry, S. (1959b). J. biol. Chem. 234, 832.

Christensen, L. R. \& Smith, D. H., jun. (1950). Proc. Soc. exp. Biol., N.Y., 74, 840.

Davies, M. C. \& Englert, M. E. (1960). J. biol. Chem. 235, 1011.

Derechin, M. (1962). Biochem. J. 82, 241.

Derechin, M., Johnson, P. \& Szuchet, S. (1962). Biochem. J. 84, 336.

Fahey, J. L., McCoy, P. F. \& Goulian, M. (1958). J. clin. Invest. 37, 272.

Fletcher, A. P. (1954). J. clin. Invest. 33, 1242.

Hagan, J. J., Ablondi, F. B. \& De Renzo, E. C. (1960). J. biol. Chem. 235, 1005.

Heidelberger, M. \& MacPherson, C. F. C. (1943). Science, 97, 405 .

Hink, J. H. \& McDonald, J. K. (1962). Abstr. Conf. Plasma Proteins and Cellular Elements of the Blood, Cambridge, Mass. Abstracted in Vox sang., Basel, 1963, 8, 103.

Kline, D. L. (1953). J. biol. Chem. 204, 949.

Kline, D. L. \& Fishman, J. B. (1961). J. biol. Chem. 236, 3232.

Linderstrøm-Lang, K. U. \& Schellman, J. A. (1959). In The Enzymes, vol. 1, 2nd ed., p. 443. Ed. by Boyer, P. D., Lardy, H. \& Myrbäck, K. New York: Academic Press Inc.

Milstone, H. A. (1941). J. Immunol. 42, 109.

Peterson, E. A. \& Sober, H. A. (1961). In Analytical Methods of Protein Chemistry, vol. 1, p. 88. Ed. by Alexander, P. \& Block, J. R. New York: Pergamon Press.

Remmert, L. F. \& Cohen, P. (1949). J. biol. Chem. 181, 431.

Robbins, K. C. \& Summaria, L. (1963). J. biol. Chem. 238, 952.

Schachman, H. K. (1959). In Ultracentrifugation in Biochemistry. New York and London: Academic Press Inc.

Sgouris, J. T., Inman, J. K., McCall, K. B., Hyndman, L. A. \& Anderson, H. D. (1960). Vox sang., Basel, 5, 357. Shulman, S. (1961). Biochim. biophys. Acta, 46, 6.

Shulman, S., Alkjaersig, N. \& Sherry, S. (1958). J. biol. Chem. 233, 91.

Svensson, H. \& Thompson, T. E. (1961). In Analytical Methods of Protein Chemistry, vol. 3, p. 58. Ed. by Alexander, P. \& Block, J. R. New York: Pergamon Press.

Wallen, P. (1962a). Ark. Kemi, 19, 451.

Wallen, P. (1962b). Ark. Kemi, 19, 469.

Wallen, P. \& Bergström, K. (1959). Acta chem. scand. 13, 1464.

Wallen, P. \& Bergström, K. (1960). Actachem. scand.14, 217. 